\title{
Patients and Nurses' Opinion about uses of physical restraint for psychiatric patients in Mental Health Hospital
}

\section{Hyam Hassan Doma}

Baccalaureate of Faculty of Nursing, Tanat University

\section{Mervat Hosny shalaby}

Assistant professor of psychiatric Metal Health Nursing,

Faculty of Nursing, Tanta University

Shereen Mohamed Abo El- yzeed Lecture of Psychiatric and Mental Health Nursing Faculty of Nursing, Tanta University

\begin{abstract}
Physical restraint is any manual method or mechanical device attached to the patient's body that restricts freedom of movement and cannot be easily removed. Despite extensive literature on the potential complications of using physical restraint, it is still considered as a permanent and effective intervention in the management of unpleasant behaviors. This study aimed to assess patients' and nurses' opinion about uses of physical restraint on psychiatric patients in Mental Health Hospital. Study was conducted in Tanta Mental Health Hospital which is affiliated to Ministry of Health. The study subjects include 49 psychiatric patient and all nurses working in Tanta Mental Health Hospital (80 nurses). Two tools were developed by the researcher to collect the necessary data. Tool (1) was Patient Structured Interview questionnaire, and Tool (2) was nurses structured Interview questionnaire. The main results revealed that a round one third of studied patients had negative opinions about use of physical restraint, and nearly half of them were average. In another hand more than half of studied nurses had positive opinion and nearly to one third were average regarding to using of physical restraints, so it was recommended that nurses should be involved in educational program about; therapeutic use of self and effective communication skills to improve their interaction with patient and encourage them to express gradually about their strong feeling, and educated about aggressive behaviors, it's dynamic and predisposing factors, and how applied physical restraints effectively with patients and debriefing following these procedure to minimize a negative effects on patients.
\end{abstract}




\section{Introduction:}

Physical restraint is any manual method or mechanical device attached to the patient's body that restricts freedom of movement and cannot be easily removed ${ }^{(1)}$. It is considered one of the earliest mean used to cope with people who are unable to control their behavior ${ }^{(2)}$. Despite extensive literature on the potential complications of using physical restraint, it is still considered as a permanent and effective intervention in the management of unpleasant behaviors on acute and long term care ${ }^{(3)}$.

One of the strongest justification for the use of physical restraints in hospital are usually for the protection of patients and others when medication and verbal therapies are insufficient to control potentially violent patients ${ }^{(4)}$. Restrain means to place patient under control when necessary to prevent serious body harm to the patient or to another person ${ }^{(5)}$.Despite physical restraint on psychiatric inpatient unite remains a highly controversial ethical issue, literature estimated that more than $20 \%$ of young and adult psychiatric patients are physically restrained at some point during their stay in the hospital ${ }^{(6)}$. In all circumstances, the least restrictive restraints should be used and restraints should never be used for the sake or convenience. In saying this, it is imperative that nurse must be understand and follow proper protocol and procedure when restraining a patients to ensure safety and dignity of the patient ${ }^{(7,8)}$.

There are several types of medical products that have been used to physically restraint patient's movement. Some of them are waist, vest, wrist or leg restraints, hand mitts, chairs with table tops, full side rails, net beds or enclosed beds, freedom' elbow splints, or tucking a patient's sheets so tightly that the patient cannot move, or tranquilizer chairs, strait jackets ${ }^{(9)}$.

Protection bed was another physical restraint it was a narrow bed, just wide enough to accommodate a person of average weight, with a lid that could be fastened to confine the patient while Blanket sheets restraint is used to restraint the whole body ${ }^{(10)}$. A more human form of physical restraint was straight waist- coast that evolved into a shaped like a jacket with overlong sleeves, the ends of these sleeves can be tied to the back of the wearer, so their arms are kept close to their chest with possibility of only little movement. Limb restraint was considered one of the types of mechanical restraint commonly used. It's either soft or leather band fastened around the ankle or leg (ankle) or around wrist or arm (wristlet) ${ }^{(11)}$. 
Physical restraints were described as "high-risk interventions with fatal consequences if applied incorrectly. One of the most dangerous moments of restrained patient is during the take down. A take down refers to when a patient is raced down and immobilized for application of a restraint. It is quick period that patient can sustained serious injury and even death. Some studies found that the largest percentage of patient assaults by staff members during restraint incidents and another documented that most staff injuries are sustained when staff are trying to control patient violence ${ }^{(12)}$.

Restraint method can have considerable harmful psychological effect on both patients and nurse. It can affect the relationship between patient and staff member, and changes the ability of nurses to preserve and interact with the patient as an individual. There is a risk of patients being a status of objects, and to be controlled regardless of their individual needs ${ }^{(13)}$.The patients who physically restrained experienced fear, demoralization, anger, resistance, powerlessness, punished, and denial. In addition to attempting to restraint may be frightening patients and increase the feeling of fear, which can be result in angry or combative behavior as well as lose of dignity and withdrawal ${ }^{(14)}$.

Nursing staff may have some emotional reaction felt while doing restraint procedure, include anxiety, anger, feeling bored or distressed, crying, inadequacy, hopelessness, frustration, fear, guilt, dissatisfaction. In another line the restraint incidents had reawakened distressing memories of pervious traumatic events to staff members, although this method is not to the satisfaction of neither patients nor nurses, nurses are inevitably forced to use it. ${ }^{(15)}$

The studies show that a wide variance exists in the frequency of this intervention is used, from one health care setting to another. One significant factor in this variance may be the opinion and experience of nurses toward its use ${ }^{(16)}$. Scherer (1991) emphasize the important of providing nurses the opportunity to reflect their feeling, and opinion about uses of physical restrain on patients. Such as opportunity for discussion of their concern, contribute to the improvement the quality of care that provided to restrained patients ${ }^{(17)}$.

Nurses are often on the front line of interacting with patients who may be violent or who display disruptive 
behaviors, some studies show that nurses may considered a physical restraint as acceptable mean of managing the destructive behavior of seriously disturbed patient ${ }^{(18)}$,or nurses feel pressured to demonstrate physical restraint as a result of feeling of anger and frustration, when their clients do not conform to their instructions, the restraints tended to occur as a result of conflict and power struggles; inflexibility, lack of negotiation skills, or an inability or unwillingness to attempt to understand patients, on the part of the staff members, and did not occur as a result of emergency situations ${ }^{(19)}$.

Despite understanding of patients, and nurses perspectives are considered important in decision making toward use physical restraints and evaluate its' effective, little researches have been conducted this aspect in using of physical restraint ${ }^{(20)}$. The process of physical restraint continues even after the restraint of the patient. It includes nursing care, to ensure prevention of patient damage, interaction with the patient for the commitment and release of restraint and also explaining to the patient reasons or need to restrain him/her. Thus it is important to determine nurses and patients' opinion toward physical restraints ${ }^{(21)}$.

\section{Aim of the study}

The aim of the study was to assess psychiatric patients and nurses' opinion about use of physical restraint on psychiatric patients in Mental Health Hospital.

\section{Research questions}

What are the opinion of psychiatric patients and nurses about uses of physical restraint on psychiatric patients in Mental Health Hospital?

\section{Materials and Method}

\section{Materials}

\section{Research design:-}

The present study follows a descriptive research design.

\section{Setting:-}

The study was conducted at Tanta Mental Health Hospital. Affiliated to Ministry of Health with capacity of (107) beds, divided in to four wards. Two ward for male (67bed) and two wards for female (40bed) This hospital serves three governorates, namely; Gharbeya , Menofeya ,and Kafr-El-sheikh .

\section{Subjects:-}

The study was selected from the previously mentioned setting and divided in two groups:-

Group one: - It was consisting of 49 psychiatric patients either male or female 
depended on power analysis equation (with power of test (90\%) and significant level $($ alpha $=0.05)$. The subjects of the study were fulfilling the following inclusion criteria:-

- Able to communicate.

-Willing to participate in the study.

- Have previous experience with physical restraint

-Duration of mental illness more than 6 months.

Group two: - all nurses working at Mental Health Hospitals (80 nurses) and fulfilling the following inclusion criteria:-

-Willing to participate in the study.

-Working experience at Mental Health Hospitals more than 2 years

-Provide direct care to psychiatric patient.

\section{Tools of the study:-}

The data of the study was collected using the following tools:

Tool (I): Patient Structured Interview questionnaire .It was developed by the researcher after review of literature to assess opinion of psychiatric patients about uses of physical restraint ${ }^{(22-25)}$. It consisted of two parts:-

Part one: - included items related to socio demographic characteristic of psychiatric patient, it included: age, sex, marital status, occupation, educational level, and clinical data such as: - duration of illness, numbers of hospitalization, and duration of current hospitalization.

Part two: - Patient Structured interview questionnaire.

This tool consisted of 26 items which measure patient's opinion regarding the experience of being restrained, the effectiveness of restraint, and the ways that patient dealing with being restrained. In this tool there consisted of 9 positive statements $\quad(15,16,17,18,20,21,22,25,26)$ and the rest statements are negative. Each statement was rated on a three point likert scale on which 1 = agree, $2=$ undecided and $3=$ disagree (The total score ranging from 26 to 78 grade (good are $>75 \%$, fair are $50-75 \%$, bad are $<50$ $\%)$. The higher score was mean more positive opinion of psychiatric patient about use of physical restraint.

\section{Tool (II): Nurses structured Interview} questionnaire. It was develop by the researcher after review of literature to assess opinion of psychiatric nurses about uses of physical restraint for psychiatric patient $^{(15,23,26)}$. It consisted of two parts:Part one: it included socio- demographic characteristics and clinical experience of nurses such as:- sex, age, marital status , level of education, and years of experience in psychiatric nursing filed, previous 
training periods, and reason for not attending in any training period.

Part two: - Nurses Structured Interview questionnaire to assess opinion of psychiatric nurses about uses of physical restraint.

This part consisted of 28 items the eleven items were positive statements $(1,2,3,11$ $, 17,19,20,24,25,27,28)$ and the rest items were negative. Each statement was rated on a three point likert scale on which $1=$ agree, 2 = undecided and $3=$ disagree. The total score was ranging from 28 to 84 grade (good are $>75 \%$, fair are 50-75\%, bad are $<50 \%)$. The higher score was a more positive opinion of psychiatric nurses toward uses of physical restraint on psychiatric patient.

\section{Method}

A written official letters from the Faculty of Nursing, Tanta University was directed to the director of Tanta Mental Health Hospital that is affiliated to Ministry of Health to take their permission for collected data. The director was informed about the goal of the study, data and time of data collection. All tools were translated into Arabic language by the researcher and were tested for translation. All tools were tested for internal validity by a jury composed of five experts in psychiatric nursing fields. The required modifications were done accordingly.

\section{Ethical Consideration;}

- Ethical written consent will be obtained from studied nurses and patients after explaining the purpose of the study.

-The subjects were informed about the goal of the study, date and time of data collection.

- Informing studied subjects about confidentiality and privacy of any information was obtained.

-Respecting the right of the studied subjects to be withdrawal at any time during data collection.

\section{Pilot study:-}

-A pilot study was carried out on five of psychiatric patients and eight nurses from Tanta Mental Health Hospital that is affiliated to Ministry of Health to ascertain the clarity, applicability and feasibility of the study tools. In addition, estimate the approximate time required for interviewing the studied subjects as well as identifying obstacles that might be faced during data collection. These subject were excluded later from the study sample. Necessary modification was done based on the finding of this pilot study.

\section{Actual Study}

-The actual study involved 49 psychiatric 
patients were selected randomly and all nurses (80 nurses) who were working at previous setting.

-The data was collected through interview with each studied subject individually to assess his or her opinion toward use of physical restraint.

-The interview with studied nurse lasted for 10-20 minute, and interview with the studied patient lasted for about 2030 minute according to their level of attention, understanding and cooperation.

-Data were collected over a period of four months starting from October 2015 and ending in January 2016.

\section{Statistical analysis;}

The collected data were organized, tabulated and statistically analyzed using SPSS version 19 (Statistical Package for Social Studies). Data were presented numbers and percentage. The range mean and standard deviations were calculated. Chi - square test was used to compare between more than two variables. Person's correlation coefficient test used to determine association between variables in the same group. The level of statically significant was adapted at $\mathrm{P} \leq 0.05$. 
Table (1):-Distribution of studied patients according to socio demographic characteristics and clinical data (no=49).

\begin{tabular}{|c|c|c|}
\hline Socio demographic characteristics & $\begin{array}{c}(n=49) \\
\text { No }\end{array}$ & $\%$ \\
\hline Gender & & \\
\hline Males & 26 & 53.1 \\
\hline Females & 23 & 46.9 \\
\hline Age : & & \\
\hline$>20$ & 3 & 6.1 \\
\hline $20-<30$ & 19 & 38.8 \\
\hline $30-<40$ & 18 & 36.7 \\
\hline $40-50$ & 9 & 18.4 \\
\hline Range & \multirow{2}{*}{\multicolumn{2}{|c|}{$\begin{array}{c}18-50 \\
30.76 \pm 8.65\end{array}$}} \\
\hline Mean \pm SD & & \\
\hline \multicolumn{3}{|l|}{ Marital status: } \\
\hline Single & 16 & 32.7 \\
\hline Married & 30 & 61.2 \\
\hline Divorced & 1 & 2.0 \\
\hline Widowed & 2 & 4.1 \\
\hline \multicolumn{3}{|l|}{ Educational level: } \\
\hline Illiterate & 4 & 8.2 \\
\hline Read \& write & 8 & 16.3 \\
\hline Primary & 13 & 26.5 \\
\hline Secondary & 19 & 38.8 \\
\hline University graduate & 5 & 10.2 \\
\hline \multicolumn{3}{|l|}{ Job: } \\
\hline Employed & 31 & 63.3 \\
\hline Not employed & 18 & 36.7 \\
\hline \multicolumn{3}{|l|}{ Duration of mental illness: } \\
\hline$<10$ & 16 & 32.6 \\
\hline $10-$ & 16 & 32.6 \\
\hline $15-$ & 7 & 14.3 \\
\hline $20-30$ & 10 & 20.5 \\
\hline Range & \multirow{3}{*}{\multicolumn{2}{|c|}{$\begin{array}{c}2-30 \\
12.41 \pm 6.34 \\
12\end{array}$}} \\
\hline Mean + SD & & \\
\hline Median & & \\
\hline Number of hospitalization: & & \\
\hline $5-$ & 7 & 14.3 \\
\hline $10-$ & 10 & 20.4 \\
\hline $15-$ & 9 & 18.4 \\
\hline $20-$ & 9 & 18.4 \\
\hline$\leq 25$ & 14 & 28.5 \\
\hline Range & \multirow{3}{*}{\multicolumn{2}{|c|}{$\begin{array}{c}5-55 \\
20.84+12.14 \\
19\end{array}$}} \\
\hline Mean \pm SD & & \\
\hline Median & & \\
\hline Duration of current hospitalization & \multirow{3}{*}{\multicolumn{2}{|c|}{$\begin{array}{c}1-10 \\
4.86 \pm 3.0\end{array}$}} \\
\hline Range of month & & \\
\hline Mean \pm SD & & \\
\hline
\end{tabular}


Table (1) clarifies distribution of patients according to their socio-demographic characteristics and clinical data. Regarding to gender, the more than half of sample $(53.1 \%)$ was male, while $(46.9 \%)$ were female. As for age, $38.8 \%$ of studied patient aged from 20 to > 30 old year and $(36.7 \%)$ of them ranged from $30-$ to $>40$, with a mean $30.76 \pm 8.65$. More than half of studies patient were married (61.2\%), and $32.71 \%$ were single. In addition to the studied patients have different level of education with different present age, $38.8 \%$ of them have secondary level of education, $26.5 \%$ have primary level, $16.3 \%$ were read \& write, $10.2 \%$ have graduate level, and only $8.2 \%$ of studied patients were illiterate. The more than half of studies patients $(63.3 \%)$ were employed. In regarding to clinical data, more than half of studies patient have duration of illness less than 15 years, with mean $12.41 \pm 6.34$, and the mean of their number of hospitalization were $20.84 \pm 12.14$. In addition to the mean of their duration in current hospitalization was 4.86+3.0.

Table (2): Distribution of studied nurses according to socio-demographic characteristics $(\mathbf{n}=\mathbf{8 0})$.

\begin{tabular}{|c|c|c|}
\hline Socio demographic characteristics & $\begin{array}{c}(\mathbf{n}=\mathbf{8 0}) \\
\text { No }\end{array}$ & $\%$ \\
\hline $\begin{array}{cc}\text { Sex: } & \\
& \text { Male } \\
\text { Female }\end{array}$ & $\begin{array}{l}34 \\
46\end{array}$ & $\begin{array}{l}42.5 \\
57.5\end{array}$ \\
\hline $\begin{array}{c}\text { Age : } \\
20-<30 \\
30-<40 \\
40-50 \\
\text { Range } \\
\text { Mean } \pm \text { SD }\end{array}$ & $\begin{array}{l}37 \\
33 \\
10\end{array}$ & $\begin{array}{l}46.2 \\
41.3 \\
12.5\end{array}$ \\
\hline $\begin{array}{c}\text { Marital status: } \\
\text { Single } \\
\text { Married } \\
\text { Divorced } \\
\text { Widow } \\
\end{array}$ & $\begin{array}{c}11 \\
53 \\
12 \\
4 \\
\end{array}$ & $\begin{array}{c}13.8 \\
66.3 \\
15.0 \\
5.0\end{array}$ \\
\hline $\begin{array}{c}\text { Educational level: } \\
\text { Diploma } \\
\text { Graduate from institute of nursing } \\
\text { Bachelor } \\
\text { Master degree }\end{array}$ & $\begin{array}{c}26 \\
30 \\
21 \\
3\end{array}$ & $\begin{array}{c}32.5 \\
37.5 \\
26.3 \\
3.8\end{array}$ \\
\hline $\begin{array}{c}\text { Years of experience in psychiatric nursing : } \\
<5 \\
5- \\
10-\end{array}$ & $\begin{array}{l}21 \\
32 \\
10\end{array}$ & $\begin{array}{l}26.3 \\
40.0 \\
12.5\end{array}$ \\
\hline
\end{tabular}




\begin{tabular}{|c|c|c|}
\hline $\begin{array}{c}15- \\
\geq 20 \\
\text { Range } \\
\text { Mean }+ \text { SD } \\
\text { Median }\end{array}$ & $\begin{array}{l}9 \\
8\end{array}$ & $\begin{array}{l}11.2 \\
10.0\end{array}$ \\
\hline $\begin{array}{l}\text { Previous training period: } \\
\text { Nurses have training } \\
\text { Nurses have not any training }\end{array}$ & $\begin{array}{l}16 \\
64\end{array}$ & $\begin{array}{l}20.0 \\
80.0\end{array}$ \\
\hline $\begin{array}{l}\text { Reasons for not attending training: } \\
\text { No training by the hospital } \\
\text { No previous advertisement before training } \\
\text { Have no time to attend training } \\
\text { High cost of training sessions } \\
\text { Have no desire to attend training } \\
\text { Not need training }\end{array}$ & $\begin{array}{c}14 \\
8 \\
7 \\
6 \\
2 \\
11\end{array}$ & $\begin{array}{c}17.5 \\
10.0 \\
8.8 \\
7.5 \\
2.5 \\
13.8\end{array}$ \\
\hline
\end{tabular}

The item" reason for not attending nurses training" is not mutually explosive

Table (2) clarifies distribution of nurses according to their socio demographic characteristics. Regarding to, gender the more than half of subjects (57.5\%) were female, while $42.5 \%$ were male. As for age $46.2 \%$ of studied nurses aged from 20 to > 30 old year, and $41.3 \%$ aged from $30->40$ with mean $31.09 \pm 6.91$. The more than half of studied nurse $(66.3 \%)$ were married, $(15 \%)$ were divorced and $(13.8 \%)$ were single. In addition to the studied nurses have different level of education with different percentage, $37.5 \%$ of them graduate from institute of nursing, $32.5 \%$ have diploma, $26.3 \%$ have bachelor, and only $3.8 \%$ have master degree. In regarding to experiences in psychiatric nursing, $26.3 \%$ of the studied nurses had experience less than five years, $40 \%$ had experiences from five to ten years, with a mean $8.70 \pm 6.03$ years and the median was 7 years. A majority of studies nurses $(80.0 \%)$ have not previous training periods of psychiatric nursing. Regarding reason for not attending training, it was clear that a various reasons such as $17.5 \%$ of nurses said that the hospital do not provide any training course, $13.8 \%$ reported that there is no need for attend these sessions. $10 \%$ of studied nurses answered by the hospital do not advertise about training courses, and (8.8\%) of nurses insisted that there is not enough time to attend such courses, $7.5 \%$ was reported that high cost of training courses, and $2.5 \%$ of studied nurses reported that there is no desire for them to attend these training sessions. 
Table (3):- Distribution of studied nurses and patients regarding to their opinions about use of physical restraint.

\begin{tabular}{|c|c|c|c|c|c|c|}
\hline \multirow{2}{*}{ Physical restraint } & \multicolumn{2}{|c|}{ Negative (<50\%) } & \multicolumn{2}{c|}{ Average (50-75\%) } & \multicolumn{2}{c|}{ Positive (>75\%) } \\
\cline { 2 - 7 } & No & $\%$ & No & $\%$ & No & $\%$ \\
\hline Patients' opinion(n=49) & 18 & 36.7 & 23 & 47.0 & 8 & 16.3 \\
\hline Nurses' opinion(n=80) & 0 & 0.0 & 27 & 33.8 & 53 & 66.2 \\
\hline
\end{tabular}

Table (3) shows distribution of studied nurses and patients regarding to their opinions about use of physical restraint. It was clear that $36.7 \%$ of studied patients had negative opinions about use of physical restraint compared with none of studied nurses, and $16.3 \%$ of studied patients had positive opinions compared with $66.2 \%$ of studied nurses, while $47 \%$ of studied patients reported average and also $33.8 \%$ of studied nurses have a same opinion

Table (4): Relation between socio- demographic characteristics of studied patients and their opinion toward physical restraint

\begin{tabular}{|c|c|c|c|c|c|c|c|}
\hline \multirow{3}{*}{$\begin{array}{c}\text { Socio- demographic } \\
\text { Characteristics }\end{array}$} & \multicolumn{7}{|c|}{ Patient opinion toward physical restraint } \\
\hline & \multicolumn{2}{|c|}{$\begin{array}{l}\text { Negative } \\
(<50 \%)\end{array}$} & \multicolumn{2}{|c|}{$\begin{array}{c}\text { Average } \\
(\mathbf{5 0 - 7 5 \% )}\end{array}$} & \multicolumn{2}{|c|}{$\begin{array}{l}\text { Positive } \\
(>75 \%)\end{array}$} & \multirow[t]{2}{*}{$\mathbf{P}$} \\
\hline & No & $\%$ & No & $\%$ & No & $\%$ & \\
\hline Gender: & & & & & & & 0.837 \\
\hline Male & 11 & 42.3 & 11 & 42.3 & 4 & 15.4 & \\
\hline Female & 7 & 30.4 & 12 & 52.2 & 4 & 17.4 & \\
\hline Age : & & & & & & & 0.367 \\
\hline$<30$ & 12 & 44.4 & 10 & 37.0 & 5 & 18.3 & \\
\hline$\geq 30$ & 6 & 23.7 & 13 & 59.1 & 3 & 13.6 & \\
\hline Marital status: & & & & & & & \\
\hline Currently not married & 7 & 36.8 & 9 & 47.4 & 3 & 15.8 & \\
\hline Currently married & 11 & 36.7 & 14 & 46.7 & 5 & 16.7 & \\
\hline Job: & & & & & & & 0.898 \\
\hline Employed & 10 & 32.3 & 16 & 51.6 & 5 & 16.1 & \\
\hline Not employed & 8 & 44.4 & 7 & 38.9 & 3 & 16.7 & \\
\hline $\begin{array}{l}\text { Educational level:- } \\
\text {-Less than secondary }\end{array}$ & & & & & & & $0.001 *$ \\
\hline -Secondary or more & 6 & 24.0 & 11 & 44.0 & 8 & 32.0 & \\
\hline & 12 & 50.0 & 12 & 50.0 & 0 & 0.0 & \\
\hline
\end{tabular}

*Statically Significant at $\geq 0.05$

Table (4) clarifies the relation between socio- demographic characteristics of patients and their opinion toward physical restrain. There were not statically significant relation between the opinion of studied patient and their gender, age, marital status, and their job, but there was a statically significant relation with their level of educational level $(\mathrm{P}=0.001)$. 
Table (5): Relation between socio-demographic characteristics of studied nurses and their opinions toward physical restraint $(\mathrm{No}=\mathbf{8 0})$

\begin{tabular}{|c|c|c|c|c|c|c|}
\hline \multirow[t]{2}{*}{ Variables } & \multicolumn{2}{|c|}{ Average } & \multicolumn{2}{|c|}{ Positive } & \multirow{2}{*}{$X^{2}$} & \multirow{2}{*}{$\mathrm{P}$} \\
\hline & No & $\%$ & No & $\%$ & & \\
\hline Age : & & & & & 6.772 & $0.009 *$ \\
\hline$<30$ & 7 & 18.9 & 30 & 81.1 & & \\
\hline$\geq 30$ & 20 & 46.5 & 23 & 53.5 & & \\
\hline Gender: & & & & & 0.498 & 0.481 \\
\hline Male & 10 & 29.4 & 20 & 70.6 & & \\
\hline Female & 17 & 37.0 & 29 & 63.3 & & \\
\hline Marital status: & & & & & 1.116 & 0.291 \\
\hline Currently not married & 7 & 25.9 & 20 & 74.1 & & \\
\hline Currently married & 20 & 37.7 & 33 & 62.3 & & \\
\hline Educational level: & & & & & 1.082 & 0.582 \\
\hline Diploma & 8 & 26.7 & 22 & 73.3 & & \\
\hline $\begin{array}{c}\text { Graduate from institute of } \\
\text { nursing }\end{array}$ & 10 & 38.5 & 16 & 61.5 & & \\
\hline Bachelor & 9 & 37.5 & 15 & 62.5 & & \\
\hline $\begin{array}{c}\text { Years of experiences in } \\
\text { psychiatric field: }\end{array}$ & & & & & 6.227 & $0.038^{*}$ \\
\hline$<5$ & 7 & 21.9 & 25 & 78.1 & & \\
\hline 5- & 6 & 28.6 & 15 & 71.4 & & \\
\hline$\geq 10$ & 14 & 51.9 & 13 & 48.1 & & \\
\hline Previous training: & & & & & 2.362 & 0.124 \\
\hline Nurses have training & 8 & 50.0 & 8 & 50.0 & & \\
\hline $\begin{array}{l}\text { Nurses have not any } \\
\text { training periods }\end{array}$ & 19 & 29.7 & 45 & 70.3 & & \\
\hline
\end{tabular}

*Statistically Significant at $\geq 0.05$

Table (5) Shows relation between socio-demographic characteristics of nurses and their opinions toward physical restrain. It was found that a statistically significant relation between nurses opinion toward physical restraint, and their age, and years of experiences in psychiatric field " $X^{2}=6.772, \mathrm{P}=0.009, " X^{2}=6.227, \mathrm{P}=0.038$ respectively" 
Table (5): Correlation between studied patients' opinion toward physical restraint and their socio demographic characteristics

\begin{tabular}{|c|c|c|}
\hline \multirow{2}{*}{ Items } & \multicolumn{2}{|c|}{ Total physical restrain opinion score } \\
\cline { 2 - 3 } & $\mathbf{R}$ & $\mathbf{P}$ \\
\hline Age in years & 0.074 & 0.613 \\
\hline Duration of mental illness & 0.215 & 0.137 \\
\hline Number of hospitalization & -0.021 & 0.887 \\
\hline Duration of current hospitalization & -0.060 & 0.683 \\
\hline Educational level & -0.377 & $0.007^{*}$ \\
\hline
\end{tabular}

*Statistically significant at $\geq 0.05$

Table (5): Show that relation between studied patients socio demographic characteristics and their opinion toward physical restraint. It was found that negative relation between positive opinion of patients toward physical restraint and their educational level $(r=-0.377 \& p=$ 0.007 )

Table (6): Correlation between the studied nurses' opinion toward physical restraint and their socio demographic characteristics.

\begin{tabular}{|c|c|c|}
\hline \multirow{2}{*}{ Items } & \multicolumn{2}{|c|}{ Total physical restrain opinion score } \\
\cline { 2 - 3 } & $\mathbf{R}$ & $\mathbf{P}$ \\
\hline Age in years & -0.234 & $0.036^{*}$ \\
\hline Years of experiences in psychiatric field & -0.197 & 0.079 \\
\hline Educational level & 0.080 & 0.480 \\
\hline
\end{tabular}

*Statistically significant at $\geq 0.05$

Table (6) appears that correlation between nurses' opinion toward restraint and their socio demographic characteristics. It was found that negative correlation between positive opinion of nurses toward physical restraint and their age $(\mathrm{p}=0.036 \& \mathrm{r}=-0.234)$. 


\section{Discussion}

Physical restraint is being used as a protective intervention in psychiatric setting to reduce risks posed by violent patients and to prevent patients from harming themselves and others, Fisher(1994) found that, restraint has deleterious psychological effect on patients and staff (27) Consequently, according to Steel(1993), this effect can influence therapeutic alliance between patient and staff, if staff members are prevented from dealing with intense feeling, such as those which may result from the use of physical restraint. It can influence their interaction, reaction and perception about procedure, and their choice for restraint as intervention. Facing staff opinion and reaction toward physical restraint, will help them involvement in philosophy of using less restrictive intervention $^{(28)}$.

Moreover, explore patient's opinion about the experience of being restrained, is very helpful. Patient who have been restrained constitute the only source of information regarding how restraint is experienced; Such patients can provide valuable information, that may complement observational data and information from staff, as to why restraint is used, whether it could have been avoided, and its outcome ${ }^{(29,30) \text {. }}$

Some studies have examined patients and nurses opinion concerning physical restraint. They indicated that, patients have negative opinion toward restraint. However, nurses have positive opinion toward applying physical restraint especially on aggressive patient ${ }^{(31-34)}$. The present study indicates that more than one third of studied patients had negative opinion about physical restraint and around half of them in border line between positive and negative opinion. The most of studied patients described physical restraint during interview as lose of freedom, punishment, humiliated and made them disable, they didn't accepted physical restraint as a way of treatment. This supported by the study of KeskValkama $\mathbf{A ( 2 0 1 0 )}$ who found that many of studied patients reported physical restraint a negative intervention and a form of retribution $^{(35)}$.

In this respect the result of the previous studies concluded that the patient who physically restrained had predominantly negative feelings such as anger, frustrated, fear, discomfort, resentment, and being not accepted or rejected. ${ }^{\mathrm{r}}$ ) In addition to feeling of helplessness, depressed or 
mixed confusion emotion as well as feeling of loneliness. ${ }^{(31-34)}$

In the same line, Meehan. $T$ et al (2002) stated that physical restraints released patients a negative thought toward staff ${ }^{(36)}$.Mohr (1998) reported that patients were empathetic for patients being restrained. ${ }^{(37)}$ Moreover, Frueh et al (2005) who added that, restraint is considered as one of the most reported life trauma that occurred within psychiatric setting as identified by patients ${ }^{(38)}$. This is also consistent with Roger (1959), who stated that the factor that necessary for patients' therapeutic improvement, is to perceive the helper as being unconditionally accepting their condition ${ }^{(39)}$, while the role of physicians and nurses in present study was frequent use of restrictive and often distressing intervention as physical restraint. This goes with Tong Chien. T et al (2004), who found that the most violent psychiatric patients wished that the staff would have been more receptive to their need $^{(40)}$.

In contrast, the study of wynn $\mathbf{R}$ (2004) who indicated that some patients reported they calmed down after having been restrained $^{(41)}$. While, Roachs (2001) who stated that restraining agitated, confused, or combative patients tend to increase behavior problem rather than calm and sooth the patients. This is explained by the fact that, a natural human reaction is resist act such as restrict movement ${ }^{(42)}$.

Regarding to nurses' opinion toward use of physical restraint, the present study indicates that, the more than half of studied nurses had positive opinion and around third in borderline, they stated that the restraints were benefits for patients, applied to protected nurses and others, its right way to control aggression, and they also satisfied about themselves when used physical restraints.

In the same line, Frost .S \& Wells . D (2000), and Huckshorn KA (2004) who found from their studies, the nurses described restraints as a best method to manage potential harm, and it's arising from a situation in which patients and others persons in unite ${ }^{(43,44)}$.In this respect Mohamed. N. F (2007) who found from his study that both physicians and nurses rationalized the use of restraint with situations where patients are dangerous to themselves or others. Noticeably, the staff was restraining patients not only in case of excitement, but also in case of aggressive behavior, while patients were still not reaching the stage of losing control. Despite ,the fact that the situations 
sometimes required other alternatives than restraint $^{(45) \text {. }}$

However, Chuang YH (2006) elicited that the most nurses in his study expressed some a struggle between patients' autonomy and their practice of care ${ }^{(46)}$. In another hand, Hantikainen .V and Kappeli.S (2000), and Lee.S et al.,(2003) who reported that their studied nurses view restraint was a necessary part of their job but it had positive and negative aspects. $(47,48)$

Moreover Mohamed N. F (2007) stated that the majority of nurses opinion was physical restraint enforces patients to obey order, this may be due to the distance and the fear provoked by the relationship between the patients and staff ${ }^{(45)}$.This is agreement with the finding of Abdel Dayem (1991), who found that the majority of nurses opinion was physical restraint helped patients to calm down and to behave better after its removal ${ }^{(49)}$.

In additional to, Mohamed N. F (2007) concluded that all nurses in his study viewed restraint has physical complication where as a minority reported psychological complication from use of restraint, and see patients childish in their behavior, and also lack sensation and feelings ${ }^{(45)}$

In another hand, the present study revealed that the level of education already influences on the patients' opinion toward used of physical restraints. The studied patients who higher level of education had negative opinion about used of physical in psychiatric hospital. This supported by the previous studies in different countries that show the high level of education effect on psychiatric patients opinion and attitude toward benefits of physical restraints, they saw it as a punishments not as a treatment (50-52)

In another line, the nurses' age and their years of experiences were a considered an important factors that influences on nurses' opinion toward used of physical restraints. This appeared in the present study, where the younger nurses with few of experiences had positive opinion toward applied restraints on hyperactive or aggressive patients, while increased age and experiences the nurses delayed the decision making toward used physical restraints in last choice. This finding was supported by Klinger V (2001) \& Husum TL et al (2010) who found the nurses with younger age and less duration of experience had more harsh attitude, and prefer restraint even hazardous admitting force $^{(53-54)}$ Moreover, nurses with higher age and more experience has constrictive attitude, refuse restraint and not agree about restraints for hyperactive patients. 
Sequira $H$ and Halstead S (2004) who

found that nurses with greater experience of implementing restraint process to intervene in aggressive incidents, able to express their opinion about causes of restraint use, but that nurses with little experience unable to express their opinion about the actual cause of implementing physical restraint ${ }^{(31)}$.

The best explanation of this finding in the present study may be lack of communication skills among younger nurses to deal effectively with patients in various situation, beside inability to use themselves as a therapeutic tool, wherein the new nurses unable to control of their emotions in stress situations, and absolved patients' anger, this lead to provocative or stimulated aggressive behaviors among frustrated patients who not met their needs or repressed their strong emotions. This explanation supported by Vythilingum.B (2009), Read.F and Fitzgeralad.L (2014)who stated that younger nurses lack of art of effective communication and empathy to handling effectively with aggressive patients. ${ }^{(55,56)}$ This is accordance with Gatheil.T (1978), who stated that the restraint as an intervention, represent the last resort, and that the earliest interventions, as talking with the patient in distressing situations, offer of support, explanation or just company, and working with the basic treatment alliance, will prevent increase tension or agitation. $^{(57)}$

\section{Conclusion}

According to the findings of the present study, it can be concluded that a round one third of studied patients had negative opinions about use of physical restraint, and nearly half of them were average. In another hand more than half of studied nurses had positive opinion and nearly to one third were average regarding to using of physical restraints.

\section{Recommendation}

Based on the results of this study, the following recommendations are suggested:-

Nurses should be involved in educational programmed about:-

1-Therapeutic use of self and effective communication skills to improve their interaction with patient and encourage them express gradually about strong feeling.

2- Aggressive behaviors, its' dynamic and predisposing factors among hospitalized psychiatric patients and how to deal effectively with those patients.

3- Nursing intervention that facilitate safe and secure environment, de-escalation 
of aggression process, conflict resolution and problem solving.

4- The alternative least restrictive methods that may be applied with patients who have history of violence.

5- Applied physical restraints effectively with patients and debriefing following this procedure to minimize a negative effect on patients who experiences of being restrained.

\section{References}

- Tebaldi C. Understanding involuntary hospitalization and use of seclusion and restraint. The Nurse Practitioner Journal .2012; 37: 13-6.

- Alty A. Nurses learning experiences and expressed opinion regarding seclusion practice. Journal of Advanced Nurses 1997; 25: 786-793.

- Gallagher A. Ethical issues in patient restraint. Nursing Times 2011; 107: 18-20.

- Wynn R . Staffs Attitudes to the use of restraint and seclusion in Norwegian University Psychiatric Hospital. Journal Nord Psychiatry. 2003; 57(6):453-459.

- Sailas EA, Wahlbeck K. Patient staff perception of restraints in hospitals.2006.

- Riley D, Mohan C, \& Whittington R. Patient restraints position in a psychiatric in patient service. Nursing Time 2006; 102(3).

- Currier GW, Allen MH. Emergency psychiatry: Physical and chemical restraint in the psychiatric emergency service. Psychiatric Services 2000; 51: 717-9.

- Perkins E, Prosser H, Riley D, Whittington R. Physical restraint in a therapeutic setting; a necessary evil?. Journal of Law Psychiatricy. 2012; 35: 43-9.

- Radziewicz MR, Amato S, Bradas C, Lorraine C. Use of Physical Restraints with Elderly Patients. 2009. Available from: http://www.consultgerirn.org/topics/p hysical_restraints/.

- Klimitz H, Uhlemann H, Fahndrich E. Are restraints used too frequently? Indications, incidence and conditions for restraint in a general psychiatric department. Psychiatric Praxis. 2009; 25(5):235-9.

- Horsburgh D. How, and when, can I restraint a patient? Journal of Post Medicine 2004; 80: 7-12.

- Baxter E, Hafner J, \& Holme G . Assaults by patients: The experiences and attitudes of psychiatric hospital nurses 2009; 26(4): 567-573. 
- Sullivan - Marex E . Psychological responses to physical restraint use in in adult . In Simpson S. Nurses and the use of restraints. Journal of Education and Aging 1999; 14(1): 75-94.

- Chien WT, Chan CW, Lam LW,\& Kam CW. Psychiatric inpatients' perceptions of positive and negative aspects of physical restraint. Patient Education and Counseling. 2005; 59:80-6.

- Difabio S. Nurse's reaction to restraining patient. Journal of American Nursing. 1998; $973-75$.

- Balevre P. Is it legal to be crazy? An ethical dilemma. Archives of psychiatric Nursing Journal. 2001;15:241-244

- Scherer. Guiding principle on restraint / Seclusion. Washington. 1991. http;//wwww.naphs.org.

- Robinson J, McCann SJ,\& Holmes HN. Nursing perception. $4^{\text {th }}$ ed; london. Lippincoll Williams \& Willkins 2004:39-43.

- Gelkop M. Attitudes, opinions, behaviors and emotions of the nursing staff toward patient restraint. Issues in mental Health Nursing. 2005, 20(6):571-86.

- Pollard R, Yanasak EV, Rogers SA, \&Tapp A. Organizational and unit factors contributing to reduction in the use of seclusion and restraint procedures on an acute psychiatric inpatient unit. Psychiatric Quarterly. 2007;78:73-81

- Bonner G, Lower T, Rawcliffe D, \& wellman N. Trauma for all: A pilot study of the subjective experience of physical restraint for mental health in patients and staff in the U. K .Journal of psychiatric and Mental Health Nursing 2002; 9: 465- 73.

- Levans L ,\& Strumpt .N. Perception of restraint use questionnaire (PRUQ). 2004. University of Pennsylvania. School of Nursing.

- Winship G. Further thoughts on the process of restraint. Journal of psychiatric and Mental Health Nursing 2006; 13: 55-60.

- MeehanT, Vermeer C, \& Windoser C. Patients' Perceptions of seclusion: a qualitative investigation. Journal of Advanced Nursing 2002; 31 (2): 370-77.

- Theoder P. Perceptions of seclusion and restraint by patients and staff in an intermediate - term care facility. Journal child and Adolescent Psychiatric nursing, 2011. http://www.findarticles.com.

- Evans L, \& Strumpt N. Primary nurse of questionnaire (PNQ).2004. 
University of Pennsylvania. School of Nursing.

- Fisher W. A review of the literature: Restraint and seclusion. Journal of American psychiatry 1994; 151(11): 1584-88.

- Steel R. Staff attitude toward seclusion and restraint: anything new? Journal of perspectives in psychiatric care $1993 ; 29(3): 23-28$.

- Karen V. Help the health care team releases its hold on restraint. Journal of Nursing Management 1999; 30(12):19-24.

- Kathleen R. Developing restraint reduction program, for child/ adolescent inpatient treatment. Journal of child and Adolescent Psychiatric Nursing. 2001. http://www.findarticles.com.

- Sequeira, H. \& Halstead, S. Control and restraint in the UK: Service user perspectives. British Journal of Forensic Practice.2002; 4, 9-18.

- Bower, F. L., McCullough, C. S. \& Timmons, M. E. A synthesis of what we know about the use of physical restraints and seclusion with patients in psychiatric and acute care.2003.

- Wong S, Tong Chien W. young medical patients' experience of physical restraint: an exploratory study. Journal of clinical Nursing.2005; 14:120-21.

- Steinert T, Lepping P, Bernhar R, Conca A, Hatling T,\& Janssen W. Incidence of seclusion and restraint in psychiatric hospitals: a literature review and survey of international trends. Social psychiatry and psychiatric epidemiology. 2010;45(9):889-97.

- Keski-Valkama A. The Use of seclusion and mechanical restraint in psychiatry: A Persistent Challenge over Time. Finland: University of Tampere; 2010.

- Meehan T, Vermeer C, \& Windsor C. Patients' perceptions of seclusion: A qualitative investigation. Journal of Advanced Nursing, 31(2), 370-377, 2002.

- Moher W, Mahon M, Noone M. A restraint on restraints: The need to reconsider the use of restrictive interventions. Journal of Archives Psychiatric nursing 1998; 12(2): 95104.

- Frueh C, Knapp R, Gusack K, Grubaugh A, Sauvageot J, cousins V, Yim E, Robins S, Monnier J, \& Hiers J. Special section on seclusion and restraint: patients of traumatic or harmful experiences in psychiatric 
setting. American psychiatric association 2005; 56:1123-33.

- Rogers C. (1959). A theory of therapy, personality and interpersonal relationship, as developed in the client centered frame work. In : Sequeira H, Simon H. Psychological effect on nursing staff of administering physical restraint in a secure psychiatric hospital.British Journal of forensic practice, 2004. http://www.findarticles .com.

- Tong Chien W, Chan L, Lam L, Kam C. Psychiatric in patients' perceptions of positive and negative aspects of physical restraint. Journal of patient Education and counseling 2004. The Nethersole School of Nursing Faculty of Medicine, the Chinese University of Hong Kong.

- Wynn R. Psychiatric Inpatients' experiences with restraint. $\mathbf{J}$ of Forensic Psychiatry and Psychology 2004; 15(1):124-44.

- Roachs S. Introductory gerontological nursing. 1sted. New York: Lippincott company, 2001:33-34.

- Frost S, Wells D. Psychiatric nurses' thoughts and feelings about restraint use: a decision dilemma. Journal of Advanced Nursing. 2000; 31(2):362-9.
- Huckshorn KA. Reducing seclusion and restraint use in mental health settings: Core strategies for prevention. Journal of Psychosocial Nursing and Mental Health Services. 2004;42:22-33.

- Mohamed N F. Reaction of patients and psychiatric hospital staff about physical restraint. Presented to Faculty of Nursing, Alexandria University 2007; 73-75.

- Chuang YH. Nurses' feelings and thoughts about using physical restraints on hospitalized psychiatric patients. Journal of Advanced Nursing. 2006;55(1):20-8.

- Hantikainen $\mathbf{V}, \&$ Kappeli S. Using restraint with nursing home residents: A qualitative study of nursing staff perceptions and decision-making. Journal of Advanced Nursing.2000, 32(5):1196-1205.

- Lee S, Gray R, Gournay K. Views of nursing staff on the use of physical restraint. Journal of Psychiatric and Mental Health Nursing. 2003;10 (4): 425-43.

- Abdel-dayem S. Nurse's opinion regarding physical restraint for psychiatric patients. High Institute of Nursing. The Second International 
Scientific Nursing Congress on Health promotion $3^{\text {rd }}$ ed; 1991.

- Chien WT, Chan CW, Lam LW, Kam CW. Found psychiatric inpatients with high level of education, perceptions of negative aspects of physical restraint. Patient Education and Counseling. 2005;59:80-6.

- Gulpers M J, Bleijlevens, M C., Ambergen T, Capezuti E,\& Van Rossum E. Belt restraint reduction in patient hospital: effects of a multicomponent intervention program. Journal of the American Geriatrics Society. 2011; 59 (11) 2029-2036.

- Kopke S, Mu“ hlhauser I, Gerlach A, Haut A, Haastert B, Mohler R., \& Meyer G. Effect of a guidelinebased multicomponent inter-vention on use of physical restraints in nursing homes: a randomized controlled trial. Journal of the American Medical Association 2012,307 (20) 21772184.

- Klinge V. Staff opinions about seclusion and restraint at a state forensic hospital, Hospital and Community Psychiatry Journal.2001, 45: 138-141.

- Husum TL, Bjorngaard JH, Finset A, \& Ruud T. A cross-sectional prospective study of seclusion, restraint and involuntary medication in acute psychiatric wards: patient, staff and ward characteristics. Health services research. 2010;10:89.

- Vgthilinyum B. before applying restraint and after. Continuing Medical Education 2009;27(10);450452.

- $\operatorname{Read}$ F, \& FitZgerald L. The mxed attitude of nurses to caring for people with mental illness in a rural general hospital International Journal Mentally Health Nursing 2014(14); 249-257.

- Gutheil T. Observation on theoretical basic for seclusion of the psychiatric inpatient. Journal of American Psychiatric Association1978; 135(3): 325-28. 